\title{
Difficulties in the design for conservation of archaeological remains: the G1 temple in My Sơn
}

\author{
L. Binda, P. Taranto \& P. Condoleo \\ Department of Structural Engineering, Politecnico di Milano, Italy
}

\begin{abstract}
To apply conservation principles to archaeological remains is a difficult task, especially when they are in a state of ruin due to destructive events, such as earthquakes, floods, storms, etc. or, even worse, wars. This was the case of the Hindu temples of the archaeological site of My Son (Vietnam); the temples were built by the Cham people from the $5^{\text {th }}$ to the $14^{\text {th }}$ century A.D., partially destroyed during various invasions from China and during wars between the Chams and the Kmers and finally badly damaged by shells during the Vietnam war.

The authors will describe their experience and try to draw some guidelines for the conservation design of these peculiar structures also those in other Vietnamese sites.
\end{abstract}

Keywords: archaeological sites, conservation principle, brick masonry, masonry joints, mechanical behaviour.

\section{Introduction}

When dealing with the preservation of historic buildings, it is difficult to prepare a design for intervention that respects all the requirements available from recommendations, guidelines and codes that have been defined during recent decades. Nevertheless, a compromise for all the requirements can usually be found. Much more difficult appears to be, according to the authors, a solution for the conservation of archaeological remains, especially when they are in a state of ruin due to lack of maintenance, destructive events, such as earthquakes, floods, storms, etc. or, even worse, when the buildings were badly destroyed by war events. 
The Hindu temples of the archaeological site of My Sơn (Vietnam) (fig.1), discovered in the $19^{\text {th }}$ century by the French architect Parmentier buried in the jungle [1], were recently badly damaged during the Vietnam war in the 1970s. The temples were built by the Cham people from the $5^{\text {th }}$ to the $14^{\text {th }}$ century A.D., partially destroyed during various invasions by the Chinese and during wars between the Chams and the Kmers and finally badly damaged by shells during the Vietnam War. Some of them are now in a state of ruin with pulverised debris.

In the case of the My Son temples, even the peculiar technique of construction using brick masonry with joints made by a natural resin created problems in the material characterisation (fig.2).

So in order to overcome the difficulties found in the study for the preservation of the remains the steps of the study were the following:

- characterisation of the materials with the study of the joint composition;

- definition of the technique of construction of the masonry;

- geometrical survey of the irregular shape with the presence of debris on top of the walls;

- definition of the principles to be respected for the conservation of the remains;

- $\quad$ study of the safety of the remains, design of the scaffolding and of the provisional structures;

- modelling of the evolution of the building and of the load carrying capacity of the remains;

- $\quad$ choice and quality control of the new materials;

- definition of the subsequent steps of intervention in order to avoid local collapses.

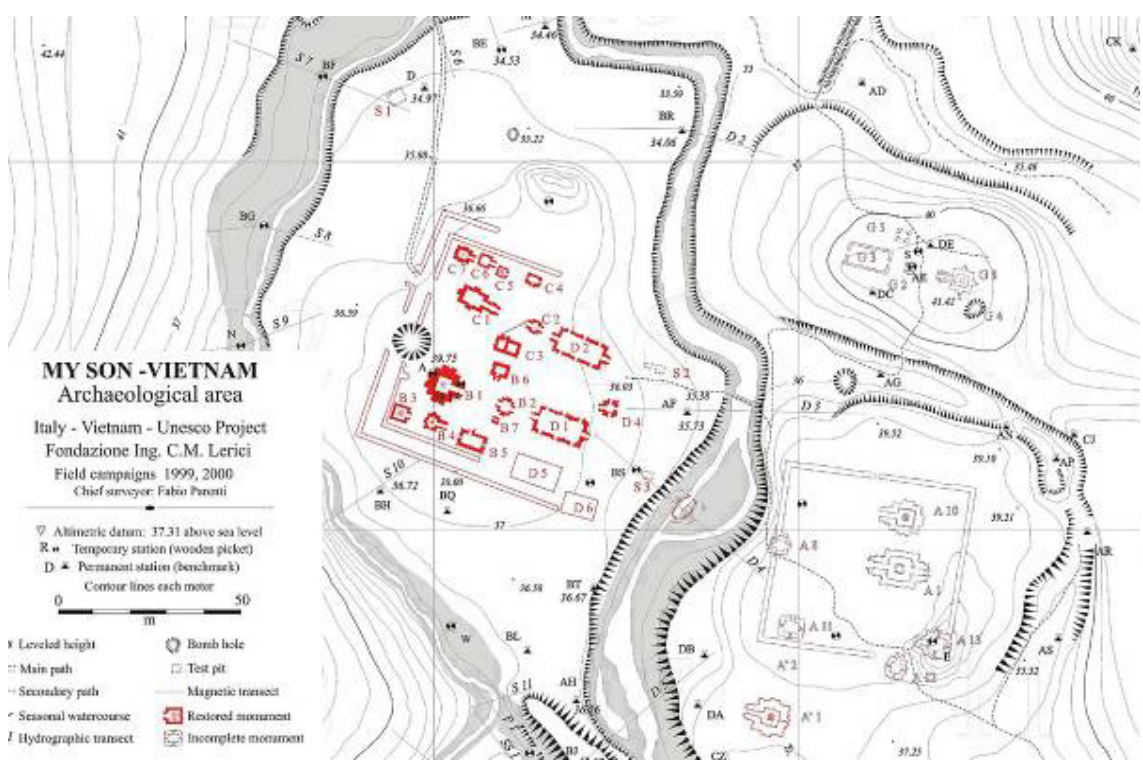

Figure 1: The archaeological area of My Sơn. 


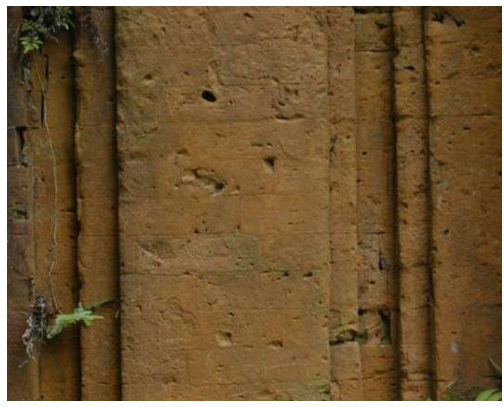

Figure 2: The thin joints between the bricks.

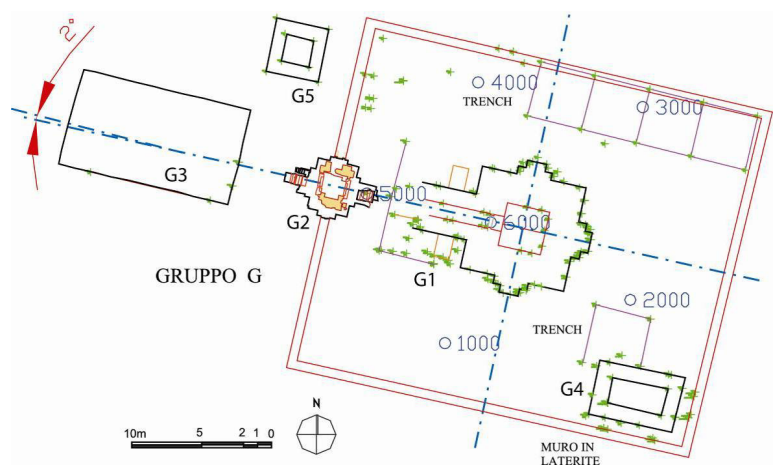

Figure 3: $\quad$ Orientation of the buildings belonging to Group G.

The works started in 2000 as an Italian pilot project for conservation of a group of buildings, the group G (fig.3), when My Son was declared by UNESCO as a world patrimony; they are still going on due to the shortage of funds from Italian and Vietnamese governments

The authors are describing in the following sections their experience and which can also be eventually used to draw some guidelines for the conservation design of these peculiar structures also in other Vietnamese sites.

\section{Characterization of the materials: the study of the joint composition}

Brick samples were taken from the material available on the soil (from buildings A1, A13, B9, D4, G1) or on the ruins (E4, E5, E7) in order to avoid spoiling the standing parts of the buildings. When possible, couplets of bricks stuck together by the original joint were collected. Following the hypothesis that the bricks were bond together using an organic binder coming from local trees, samples of vegetal materials were also collected for laboratory research.

In 2001 also a special glue from vegetal origin used for calking of boats was bought at the local market in Hoi-an; in 2004 another resin coming from local trees and sold as glue was bought close to My Sơn site. 
The composition of the brick samples detected by chemical and optical analyses is similar, which means that the material used is basically the same, even though coming from buildings of different historical periods: group A from the $7^{\text {th }} \mathrm{C}$., group $\mathrm{G}$ from the $12^{\text {th }} \mathrm{C}$. The low quantity of calcium oxide and of $\mathrm{CO}_{2}$ allows one to exclude the presence of lime in the joint.

Physical tests were carried out on small brick cubes (40mm side) cut from the bricks; the tests were carried out according to the Italian Code UNI 8942. The results show a certain in-homogeneity; nevertheless some orientation values can be given: (i) bulk density $=1,600 \mathrm{~kg} / \mathrm{m}^{3}$, (ii), I.R.S from 1.13 to $2.01 \mathrm{~kg} / \mathrm{m}^{2} / \mathrm{min}$, (iii), water absorption coefficient $=0.990 \mathrm{~g} / \mathrm{cm}^{2} \cdot \mathrm{h}^{1 / 2}$, (iv) water absorption by total immersion between 17.15 and $30.92 \%$.

Information coming from the XRD and also by firing some specimens at above $900^{\circ} \mathrm{C}$ confirm the fact that the bricks were fired at a temperature below $900^{\circ} \mathrm{C}$.

Compression tests were carried out on cubes $(40 \times 40 \times 40 \mathrm{~mm})$. Once again all the values were very much scattered, between 8 and $14 \mathrm{~N} / \mathrm{mm}^{2}$ (fig. 4 ).

The modulus of elasticity $\mathrm{E}$ and the Poisson coefficient were also calculated and the values are typical of a rather soft material.

The compression test carried out on a couplet of bricks with the joint has been compared with a test carried out on a couplet of bricks without the joint. The strength values found for the couplet without joint are lower than the ones obtained with the jointed couplet showing the good role of the thin joint when well bonded to the bricks. Furthermore, the strength of the couplets was very much similar to the strength of the single bricks, showing that the thin joint, differently from a normal mortar joint, is maintaining the rather high strength of the masonry $[2,3]$.

The most difficult problem was the identification of the organic material used for the joints. Two independent research groups in Italy have carried out physical-chemical analyses using different techniques. It is obvious that 'natural products' consist of an extremely complex mixture of chemical compounds from natural biosynthesis. So it was impossible to identify all the components. Nevertheless only the qualitative and, when possible, quantitative identification of the main products, with the relative concentrations was required. Gas chromatography, mass spectrometry, thin layer chromatography and nuclear magnetic resonance spectroscopy were used on various samples, together with FTIR and Raman spectroscopy.

The first liquid resin of Hoian (RES1) available in the local market, generally used to caulk boats, was obtained from Dipterocarpaceae trees, which commonly grow in Vietnam. The essential oils extracted from these classes of trees generally consist mostly of dammarenediol mixed with other chemical precursors. From the analyses RES1 turns out to consist of a volatile and a nonvolatile fraction. The main component $(87 \%)$ of the volatile fraction has been identified as alloaromadendrene, while the remaining $13 \%$ is a mixture of chemically related precursors and derivatives. The non-volatile fraction consists of a mixture of alloaromadendrene, dipterocarpol, dammarenediol, spatulenol and many other minor components. A second resin coming directly from the Daù 
Raì tree (Dipterocarpus alatus) was also examined and showed a very similar composition to RES1.

The material extracted with solvent from the joints was analysed and found to contain organic matter, the highest percentage being dammarenediol, also found in RES1. Spectroscopic analysis of different materials was also carried out (fig.5). The infrared spectrum of the non-volatile fraction of the commercial RES1 is very similar, but not identical, to the infrared spectrum of the organic fraction from the joints of the bricks. The differences indicate the existence of longchain alkyl residues as well a modification of the carbonyl group in the molecules. The observed spectral changes could be associated with chemical change due to oxidative processes which might have occurred in the joints over the centuries $[3,4]$.

Finally the resin coming from the Daù Raì tree was chosen.

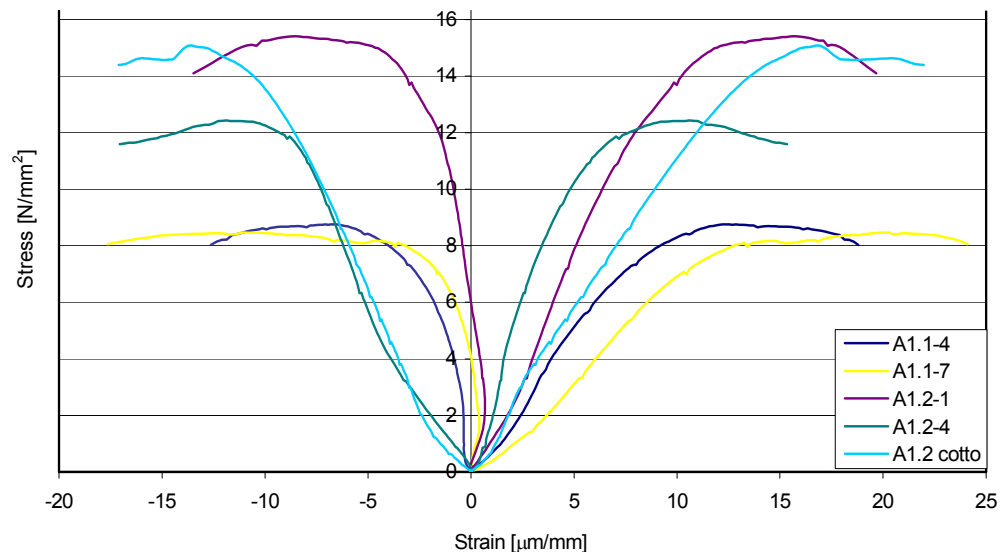

Figure 4: $\quad$ Brick - compression test on cubes $(40 \times 40 \times 40 \mathrm{~mm})$.

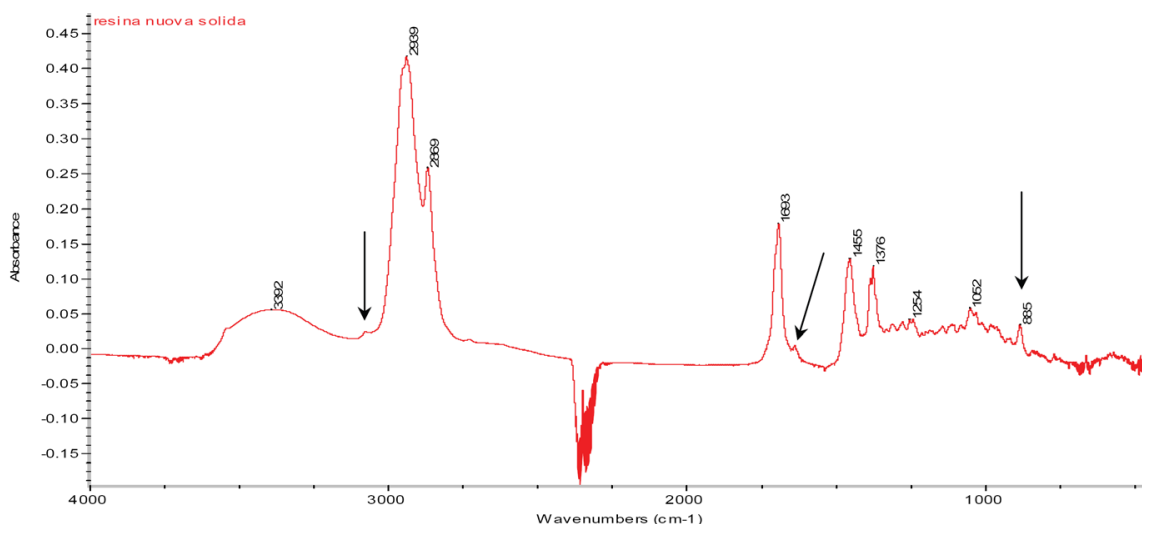

Figure 5: FT-IR spectrum of the solid residue after evaporation. 


\section{Study and definition of the masonry construction technique}

The understanding of the principles of the construction technique was the result of a thorough on-site investigation, with archaeological excavations, direct observations, and accurate photographic and geometrical surveys [5].

All the monuments in the My Son area are characterized by four fundamental parts: the foundations, the base, the central body and the roof. The internal floor plan was always located at the end of the base (cymatium); the access was made possible by stairs, generally made of stone, with the exception of the pośa, which had no access according to its function.

The foundations, which were accurately investigated in group $\mathrm{G}$ and building E7, were placed inside a slot dug in the ground. They are mainly shallow, with a depth varying from 15 to $30 \mathrm{~cm}$. Underneath, a preparation layer made of sand mixed with soil and, occasionally, ceramics was found.

The other three parts generally consist of masonry of fired bricks with thin joints. Stones were used almost exclusively for lintels, opening frames and decorative elements, with the exception of temple B1, which was completely made of stone.

The masonry in elevation is composed by three leaves (fig.6a). The two external leaves have a thickness equal to the brick length, and consist of entire bricks with very thin (micrometric) joints of natural resin. Both horizontally and vertically the bricks are so tightly bonded that joints are hardly visible. It is worth remarking that this technique enhances the protection of the walls from the biological attack of the vegetation, as long as the joints are not damaged.

The dimension of the internal leaf, as well as the type of internal filling, varies with the maximum dimension of the masonry: unlike the external leaves, which are homogeneous along the height of the temple, the internal leaf has different characteristics from the base to the principal body.

The external leaf consists of horizontal and continuous layers of headers. Only in few cases stretchers are found, to provide some toothing between the leaves (fig.6b).

The roofs change considerably from one building to the other, and differ mainly for the adopted construction technique: most of the buildings had false masonry vaults; others had probably timber double-pitch roofs covered with tiles, although no examples are left.

\section{Geometrica1 survey of the irregular shape with the presence of debris on top of the walls}

Both aims of documentation and conservation of the monument required the provision of a 3-D digital reconstruction. Within the conservation activity this tool was aimed at allowing for an effective evaluation of the most critical structural alterations and weaknesses being suffered by the monument.

Therefore focus was made on the description of the geometrical alterations and irregularities presumably related to structural problems whilst decorative surfaces were neglected due to the unfavourable combination of the high timeconsumption and poor effectiveness of their reproduction. 


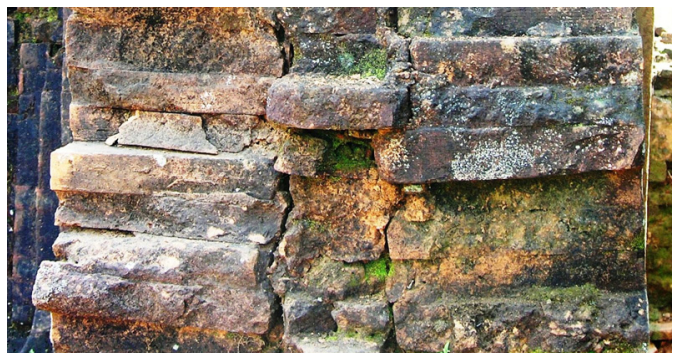

a)

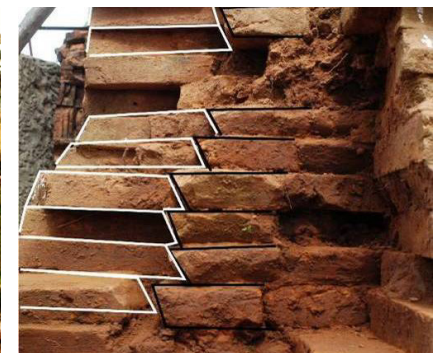

b)

Figure 6: a) Vertical section of the wall of the principal body of G1; b) toothing between the external and the internal leaf.

For the photogrammetric description of the geometry use was made of a commercial software (PhotoModeler Scanner, Eos Systems). The model was generated by acquiring the positions of over 5200 points identified by means of 27 photographs taken along radial directions, the average number of points per photograph amounting to 447. Critical points were identified on a large number of pictures (even more than 5) [6].

The pictures had been taken under two different light conditions, which helped the image interpretation. The pictures taken at midday time were used for data elaboration while the afternoon ones served as a comparison tool. In some cases visual inspection was necessary to corroborate the interpretation of the images.

Once the geometry of the structure had been reproduced by the photogrammetry survey program, the model was converted to AutoCAD drawing for further elaboration. In this context, some details, whose consideration would not have been possible or precise in the photogrammetric survey, were implemented. The obtained model is suitable for import in structural analysis codes (fig.7).

\section{Definition of the principles to be respected for the conservation of the remains}

Once the experimental research was carried out, it was decided to start the intervention from the ruins of the building G3, one of the most damaged, in order to test in reality the fitness of the materials and of the technique of intervention. Some principles for the conservation project were adopted together with the Vietnamese experts; they can be summarized as follows:

- to preserve the remaining parts of the collapsed G3 as much as possible by repair and local consolidation;

- to reconstruct by a type of anastylosis the sections where stability or durability problems are present leaving intact the present profile of the ruins as much as possible;

- to maintain the original masonry adding a new binding only when necessary; 


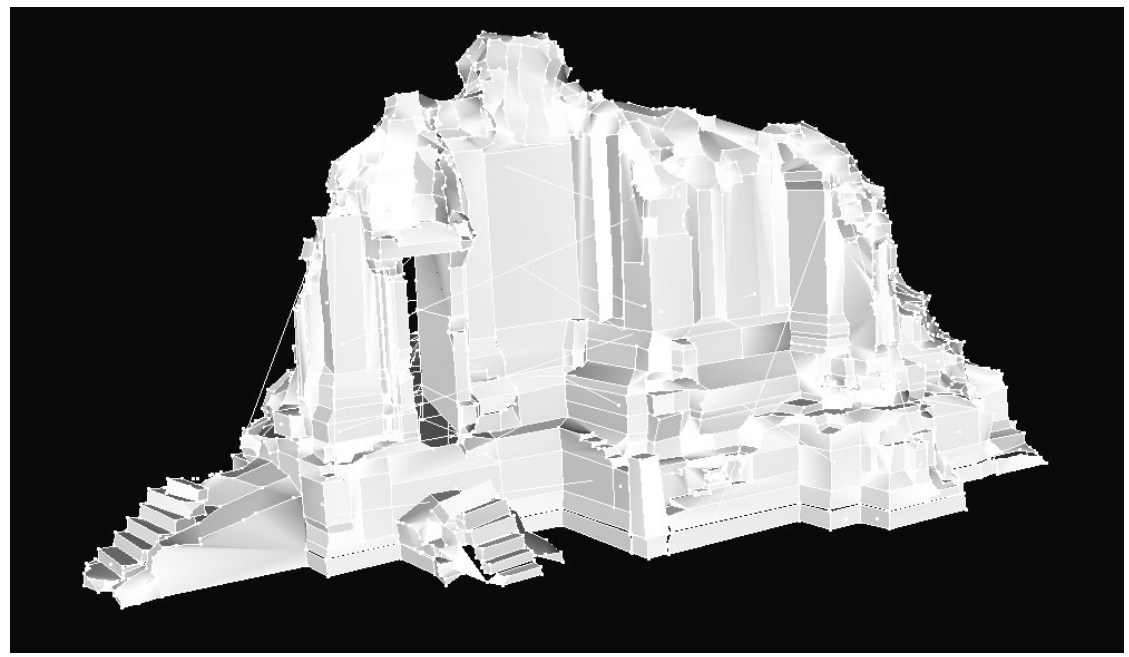

Figure 7: $\quad 3 \mathrm{D}$ model of the kalan G1 - south-west side view.

- to use new bricks, well distinguished from the old ones only in case of dangerous stability deficiency.

The listed principles brought to the following decisions: (i) the bricks should be recovered as much as possible on site in place where the walls were partially collapsed, (ii) the joints could be realized in two different ways: a) with natural resin for the external leaves of the walls, b) with a mortar made of lime and brick powder (in case the original bricks would be pozzolanic) for the internal leaf of the walls where complete brick and brick fragment would be used to fill the gaps.

\section{Modelling of the evolution of the building and of the load carrying capacity of the remains}

A number of linear elastic analyses were previously carried out in order to investigate the structural response of the temple both in its original intact configuration and the current state of ruin. The mechanical properties used in the analyses for the different masonry leaves and the stone elements were based respectively on the results of the mechanical laboratory tests performed and on literature sources. A conservative approach suggested increasing the bulk density of the bricks (by $\approx 40 \%$ ).

The numerical models took into account the layered nature of masonry under two extreme assumptions for its section (perfectly bonded or independent adjacent leaves).

The simulation of the structural response of the temple in its present state was aimed at assessing its current safety in order to avoid any further collapse. A simplified numerical model of the remains of the temple was made to estimate 
the current stress conditions. Extremely low stresses were computed even under the most conservative assumption that external and internal leaves are independent. This would indicate that the remains of the temple do not exhibit any tendency to collapse further. This result, however, assumes the integrity of the individual layers, which are actually cut by several cracks into distinct parts and the absence of local disruption phenomena in the structure. The structural safety of the ruins is therefore connected to the recovery of its integrity [7].

\section{Choice and quality control of the new materials}

The effectiveness of the second resin from Daù Raì tree, used commercially as an adhesive in the area of My Sơn, was tested at DIS Laboratory in Milan, where it was used without heating or modifying it. Fourteen specimens made with two portions of brick from My Sơn (80x40x50 mm) glued together with the chosen natural resin were prepared and cured under different conditions, in order to simulate the local climate in My Son. Specimens were prepared with joint thickness varying from 0.5 to $3 \mathrm{~mm}$, in order to test the influence of the thickness variation which can occur on site. After gluing they were left under a low compression load for two days curing. Then they were submitted to cycles under different temperature and $\mathrm{RH}$ in a climatic chamber. At the end of the treatments tensile testing was done. The results showed that the resin could be safely used also on site [4].

The mortar used in the internal joints also required a long lasting work due to the fact that an appropriate hydrated lime in Vietnam was found with great difficulty. The recovered bricks buried in the ground of group $\mathrm{G}$ were found to be pozzolanic and the prepared mortar was found to be hydraulic [8].

\section{Definition of the subsequent steps of intervention in order to avoid local collapses}

In order to avert local collapses which may endanger the overall safety of the structure, a conservation activity project was elaborated.

Due to the necessity of clearly defining not only the content of the single intervention measures but also the details of their operative coordination and temporal succession, a precise planning had to be carried out.

According to the methodology and the general philosophy applied to date, the intervention measures are aimed at the conservation and stabilization of the structure with as few alterations as possible and with the maximum possible preservation of the original morphologic and material features of the artefact.

For the definition of the regions of the structure on which intervention has to be performed, reference was made to the vast evidence of survey activities (3Dmodel, photographic documentation, past visual inspections, on field reports). Accordingly, graphic documentation, based on plans and three-dimensional views at different scale levels, indicating the points of interventions was produced: every single zone of intervention was identified by a letter. 


\begin{tabular}{|c|c|}
\hline \multicolumn{2}{|c|}{ North side Pillar strip - Intervention E } \\
\hline Intervention & Description \\
\hline Before & Present condition \\
\hline & $\begin{array}{l}\text { The north side pillar strip of the main body of the } \\
\text { temple exhibits large morphological defects which } \\
\text { endanger the local and global stability of the } \\
\text { structure. The main problem is connected to the } \\
\text { large void and disruption of the wall texture at the } \\
\text { base of the element. The upper part of the } \\
\text { elements is affected by detachments and diffused } \\
\text { damage. } \\
\text { On the upper part a vegetal root caused } \\
\text { detachment of a brick block. }\end{array}$ \\
\hline After & Features of intervention \\
\hline & $\begin{array}{l}\text { The intervention has to be focused on the } \\
\text { recovery of the structural function of the element } \\
\text { by means of the reconstruction of its base. This } \\
\text { operation entails the filling of the displayed } \\
\text { lacuna and the consolidation of the surrounding } \\
\text { wall area. } \\
\text { Removal of the above-mentioned vegetal remains, } \\
\text { cleaning and reassembling of the upper part of the } \\
\text { element has to be carried out. } \\
\text { Intervention has to proceed upward. }\end{array}$ \\
\hline
\end{tabular}

Figure 8: Example of a template regarding intervention on an external pilaster. 
For better understanding by the working teams, the interventions in each zone were described by templates. On each template, graphic and photographic documentation was provided to identify the point of intervention, and the typology of conservation activity. Two explanatory sections are present: the first one provides details on the current damage and problems of the considered region/part while the second one points out the extent, features and operative details of the single intervention measure to be performed.

A schedule of the interventions is forecast with the aim of helping coordination and optimization of the working activity and to avoid interferences and wrong practices which may endanger both the safety of workers and the stability of the monument.

In the following an example of the above mentioned templates is illustrated (fig.8).

\section{Conclusions}

The project for conservation of Group G of the My Sorn archaeological site has been described showing the difficulties which can be found when dealing with archaeological ruins. In the specific case the two most important problems found were the individuation of the peculiar material used by the Cham people in the joints of the brick masonry, the second one was how to approach the intervention without causing collapses to the precarious situation of the buildings reduced to ruins by the previous war. In the meantime it had to be clarified which were the principles adopted for the conservation project in the trial of respecting as much as possible the original remains.

Finally it must be said that this was a very stimulating experience also for the young researchers and students working on the field.

\section{Acknowledgements}

The authors wish to thank the Italian group of archaeologists directed by $\mathrm{P}$. Zolese and M. Cucarzi, Prof. K. Hoàng Đạo, P. Pichard, Dr. V. Lê Thành, N. Dang Khanh and all the Vietnamese architects, technicians and workers who provided always a hard work and the maximum support. The research was supported by the Italian Ministry of Foreign Affairs.

\section{References}

[1] Parmentier, H., Inventaire descriptif des monuments čams de l'Annam, Voll. 1-2, E. Leroux: Paris, 1909-1918.

[2] Ballio, G., Baronio, G., Binda, L., First Results on the Characterisation of Bricks and Mortars from My Son Monuments. Int. Conf./Workshop: Conserving the Past, Vietnam, pp. 204-213, 2001.

[3] Binda, L., Tedeschi, C., Condoleo, P., Mannucci E., Zerbi G., The My Sơn temples in Vietnam: study of the materials for the preservation project. Conservation Science 2007, Politecnico di Milano: Milano, 2007 
14 Structural Studies, Repairs and Maintenance of Heritage Architecture XI

[4] Binda, L., Zerbi, G., Condoleo, P. Mannucci, E., Tedeschi, C., Study of a natural resin used as joint for the brick masonry of Hindu Temples in My Son (Vietnam). 14th Int. Brick Block Masonry Conf. (14IBMAC), Manly Pacific Sydney, Australia.

[5] Condoleo, P., I templi di My Son: indagini e progetto di conservazione del Gruppo $G, \mathrm{PhD}$ thesis in Preservation of Culture Heritage of Architecture Politecnico di Milan, 2007.

[6] Barazzetti, L., Binda, L., Cucchi, M., Scaioni, M., Taranto, P., Photogrammetric reconstruction of the My Son "G1" temple in Vietnam, International Workshop 3D-ARCH 2009, Trento, Italy, 2009.

[7] Condoleo, P., Taliercio, A., Binda, L., Past and current stress conditions of temple g1 in My Sơn, Vietnam. Int. RILEM on Site Assessment of Concrete, Masonry and Timber Structures 2008, Varenna (LC), pp. 913-922, 2008.

[8] Binda, L., Condoleo, P., Tedeschi, C., Materials characterization (Chapter 10). Champa and the Archaeology of My Son (Vietnam), NUS: Singapore, pp. 283311, 2009. 